\title{
DIEGESIS E FETICHISMO DA MERCADORIA NOS JOGOS ELETRÔNICOS
}

\section{DIEGESIS AND COMMODITYFETISHISM IN ELETRONIC GAMES}

\author{
Fernando Emboaba de Camargo
}

\begin{abstract}
RESUMO
Por meio da apreensão do conceito de diegesis, somos capazes de analisarmos os jogos eletrônicos e encontrarmos diversos aspectos miméticos à nossa sociedade ocidental. Isso apenas é possível pela forma em que essa diegesis se comporta nos jogos eletrônicos e que, juntamente com a intensa interação, proporciona a ilusão de veracidade do mundo ficcional exposto e "vivenciado". Com isso, alguns aspectos cotidianos da sociedade ocidental são transpostos naturalmente para esse outro universo, como, por exemplo, o consumo de mercadorias, que no século XXI abrange produtos virtuais encontradas em diferentes mundos ficcionais de variados jogos eletrônicos trazendo, então, o dito fetichismo da mercadoria, termo criado e desenvolvido por Karl Marx. Nossa proposta, em vista disso, pretende verificar essas questões nos suportes para jogos eletrônico (computador e consoles) e no mundo ficcional do jogo eletrônico Dota 2, porque possui um mercado de compra/ venda e troca entre seus jogadores e nele podemos levantar algumas questões referentes ao fetichismo da mercadoria.
\end{abstract}

Palavras-chave: Fetichismo da mercadoria; diegesis; jogos eletrônicos.

\begin{abstract}
By understanding diegesis, we can look at games and find many mimetic aspects of Western society. The fictional world in games provided by the idea of diegesis contains an intense interaction with its players providing them the illusion of veracity of this diegetic world. Some everyday aspects from the $21^{\text {st }}$ century are translated naturally into this other universe; for example, commodity fetishism, a term created and developed by Karl Marx, which is shown in different games, in each of their different fictional worlds. Thus, this research aims to analyze these issues using as material of study computers and videogames as well as the fictional world of the game Dota 2. This game was chosen because it has a purchase/sale and exchange market between its players. This allows us to demonstrate some aspects of the commodity fetishism.
\end{abstract}

Keywords: Commodity fetishism; diegesis; electronic games.

`Doutorando em Música pela Universidade Estadual de Campinas (UNICAMP) 


\section{Introdução}

O termo diegesis apresentou-se nas escrituras gregas com os primórdios em Platão. Sua atribuição enquanto narração de um mundo ficcional modificouse até atingir o universo cinematográfico, que por sua vez, nos permitiu transpor essas teorias para os jogos eletrônicos. No entanto, a diegesis no cinema e nos jogos eletrônicos manifesta-se de maneira distinta; os filmes expõem-se por meio de cortes constantes e arbitrários, já os jogos eletrônicos demonstram uma diegesis com poucos cortes sendo que, esses cortes, são previstos e até controlados pelo jogador, fator este que permite que os mundos ficcionais dos jogos eletrônicos assemelharem-se com nosso mundo real. Através dessa afirmação, sobre uma perspectiva sociológica, percebemos a atribuição de valores de mercadoria e aspectos capitalistas na diegesis dos jogos eletrônicos evidenciado pelo fetichismoda mercadoria (termo criado por Karl Marx para explicar as relações sociais formatadas no e pelo capitalismo). Por entre essas constatações, os jogos eletrônicos ocasionam um grande impacto no cotidiano dos usuários de jogos gerando com isso novas profissões virtuais, como, por exemplo, o gold farmer (fazendeiro de ouro), no qual consiste em receber dinheiro virtual com o tempo de jogo e vendê-lo por dinheiro do nosso mundo real. Para discorrer sobre todas essas questões utilizaremos, como fundamentação teórica, David Mira, Jacyntho Lins Brandão, Cláudia Gorbman para apreendermos o conceito de diegesis; Walter Murch sobre a atribuição da diegesis no cinema com suas colocações sobre edição de filmes com enfoque nos cortes; Jesper Juul para teorias dos jogos eletrônicos; e sobre o fetichismo da mercadoria e paradigmas de consumo de nossa sociedade ocidental contemporânea, utilizaremos o próprio Karl Marx, Baudrillard, Gilles Lipovetsk e Karel Kosik. Nesse interim, como objeto de estudo, abarcaremos duas reportagens retiradas de revistas virtuais, nas quais discorrem sobre o gold farmer (fazendeiro de ouro) e sua inserção no sistema econômico, bem como o mercado virtual disponibilizado pela Steam, analisando o fetichismo da mercadoria no jogo eletrônico Dota 2 e nos suportes tecnológico dos jogos eletrônicos (computadores e consoles).

\section{Discussão sobre o termo e conceito de diegesis}

O conceito de diegesis deriva do verbo diegeîsthai o qual contempla diversos significados:

diegeîsthai pode apresentar as seguintes acepções: a) diegeîsthai um sonho (contar um sonho); b) diegeîsthai o que se viu (contar o que se viu); c) diegeîsthai acontecimentos, com destaque para fazê-lo na Assembléia ou no tribunal (narrar ou descrever); d) diegeîsthai uma situação (descrever); e) diegeîsthai o modo de ser de alguém (descrever); f) diegeîsthai a beleza de alguém (descrever); g) diegeîsthai um caráter, neste caso, o de Sócrates (descrever); i) diegeîsthai uma vida (narrar e descrever); j) diegeîsthai a natureza, o corpo, a saúde e a doença (expor); 1) diegeîsthai as motivações de alguém num tribunal (expor); m) diegeîsthaium plano (expor); n) diegeîsthai um argumento (expor); o) diegeîsthai com alguém, em uso intransitivo (conversar) (BRANDÃO, 2007, p.356).

A primeira atribuição do conceito diegesis encontra-se em Platão, contudo isso não significa que o termo não foi utilizado antes dele como discorre Jacyntho Lins Brandão (2007) "a própria palavra diégesis não se registra antes de Platão, o que poderia sugerir que este a tivesse criado ou, pelo menos, que podia transportá-la para o núcleo de sua teoria poética".

Platão distinguiu o conceito de diegesis em três categorias: diegesis simples; diegésis mimética; diegesis mista.

Por um lado temos uma diegese mista (diégesisdi' amphoterôn), exposição que alterna entre os dois géneros de léxis, contendo uma parte verbal e uma parte mimética, equivalente à epopeia (A Odisseia de Homero). Por outro, uma diegese mimética (diégesis dia mimèseôs), "a narrativa que só comporta a mimese" (Aumount, 2005:118) e cujo logos é apresentado maioritariamente através da imitação, equivalente às artes representativas (a tragédia ou a comédia). Por último, temos a diegese simples (haplèdiégesis), a narrativa que exclui a mimese, que equivale ao ditirambo, do qual não se tem uma definição precisa (MIRA, 2012, p.5).

Como atentamos na taxonomia de Platão, um termo confluente com a idéia da diegesis é o denominado mimese (representar/ imitar), também 
introduzida por Platão, contemplada e priorizada pelo filósofo Aristóteles. O significado de mimese tratado por Aristóteles consiste na imitação enquanto um agente criador que não tem a finalidade de gerar réplicas, mas promover a "restituição da forma própria universal" e "pelo reconhecimento que desencadeia, o contemplador obtém prazer, reencontrando a compreensão primeira, a do artista" (MIRA, 2012).

$\mathrm{Na}$ teoria cinematográfica o conceito de diegesis obtém significado semelhante daquele no qual foi atribuído por Platão. Segundo a teórica Cláudia Gorbman (1987: p.3) a diegesis de um filme seria " $a$ story world - a place of action" (uma história de um mundo - um local de ações). Ou seja, uma narração de fatos na qual existe na imaginação nos indivíduos, já que se sustenta por suas próprias leis físicas e caminhos históricos (sequência de fatos), seguindo ou não as influências de nosso mundo real. A mimese no contexto cinematográfico depende do material utilizado em função da narração e criação do filme. Sua tendência pode apontar para três fatores discorridos por Platão: diegesismista, diegesis mimética, diegesis simples.

Em uma diegésis mimética, por exemplo, citaremos o filme Apocalypse Now (1979) - o qual baseia-se na guerra do Vietnã, fato histórico ocorrido no Sudeste Asiático entre os anos de 1955 e 1975 . O filme situa-se no ano de 1969 e demonstra diversas situações geradas pela brutalidade da guerra, entretanto, mesmo baseando-se em um fato real, é apenas uma representação de uma diegesis mimética, ou seja, uma interpretação da história da guerra baseado nos registros da época. Em uma diegésis mista, ressaltaremos o filme A Odisséia (1997), pois sua diegesis incorpora criaturas mitológicas, deuses e fenômenos supernaturais, logo sua mimese não se restringe ao nosso mundo real incorporando diversas influências da diegesis da mitologia grega. Por fim, temos a diegesis simples que não incorpora nenhum fator mimético baseando-se apenas na diegesis que é criada.

se há poesia (poíesis) há diegese (também, recorde-se, se há mitologia). Mas esta não se reduz a "narrativa", no sentido restrito como a entendemos, podendo englobar todas as formas de exposição: um poema de Safo (por exemplo, o famoso phaínetaí moi) ou uma elegia de Sólon são tão diegéticos quanto os poemas de Homero ou as tragédias de Sófocles, com a diferença de que, neles, não há mimese, enquanto representação do discurso do outro, pois é só o poeta quem fala como si mesmo, sem se "fazer semelhante a um outro pela voz ou pelo gesto" e "jamais se ocultando (conforme a definição de mimese em Rep. 393c) (BRANDÃO, 2007, p.365).

Essas três categorias desenvolvidas por Platão não se restringem apenas aos filmes. Conseguimos encontrar a diegesis em qualquer meio de comunicação e arte que propõe um mundo ficcional nas quais obtém suas próprias trajetórias de fatos e fenômenos físicos como: filme, livros, contos da memória oral, peças de teatro e jogos eletrônicos.

Encontramos situações em que essas diversas formas de comunicação e arte compartilham a mesma diegesis. Um exemplo disso é a própria mitologia grega, na qual apresenta-se inicialmente na tradição oral e nos livros escritos na Grécia Antiga para que no século XX fosse transposta para diversos filmes e jogos eletrônicos. A diegesis nesse caso, demonstrase semelhante em todos esses suportes, não obstante, por causa da diferença de exposição de materiais e narrativa única de cada meio de comunicação, ela, a diegesis, pode sofrer diversas mudanças em seu discurso.

\section{A diegesis no cinema e nos jogos eletrônicos}

A diegesis nos filmes se manifesta de forma distinta da dos jogos eletrônicos devido ao uso constante de cortes. Por intermédio das colocações de Walter Murch (2004) em Num piscar de olhos percebemos o impacto do corte desde pós-produção do filme até a compreensão do expectador para com o mesmo.

A verdade é que um filme está sendo efetivamente cortado 24 vezes por segundo. Cada quadro é um deslocamento do anterior. Acontece que num plano contínuo, o deslocamento espaço/tempo de um quadro para o outro é tão pequeno (20 milésimos de segundos) que o público o vê como uma continuidade dentro de um mesmo contexto, em vez de 24 contextos diferentes por segundo (MURCH, 2004, p.18).

Esses cortes são decididos e efetuados após o processo de filmagem, na qual se obtém o material 
bruto. Como exemplo consideremos a pós-produção do filme Apocalypse Now, que contou com um pouco mais de 230 horas de material filmado sendo que o filme concluído possui 2 horas e 24 minutos. Para efetuar esses cortes o editor, que no caso é o próprio autor do livro Num piscar de olhos, divide em seis prioridades as escolhas e formas de efetuar um bom corte (MURCH, 2004): 1) reflete a emoção do momento; 2) faz o enredo avançar; 3) acontece no momento "certo", dá ritmo; 4) respeita o que podemos chamar de "alvo de imagem" (eye trace) - a preocupação com o foco de interesse do espectador e sua movimentação dentro do quadro; 5) respeitar a "planariedade" - a gramática das três dimensões transpostas para duas pela fotografia (a questão da linha de eixo, stageline, etc.); 6) respeitar a continuidade tridimensional do próprio espaço (onde as pessoas estão na sala e em relação umas com as outras)

A escolha dos cortes reflete diretamente na compreensão da narrativa discorrida em um filme, bem como gera significados adicionais dependendo do tipo de corte. Como exemplo disso, levantamos a primeira cena do filme O poderoso Chefão (título original: The Godfather, 1972).

Inicia-se com uma tela preta durante treze segundos até que a voz de um homem diz: " $E u$ acredito na América, a América fez minha fortuna e eu criei minha filha no estilo americano. Eu a dei liberdade, mas a ensinei nunca desonrar sua familia". Em conjunto com a fala, a câmera vai se afastando até apresentar no ecrã um rosto de um homem que, aflito, discorre sobre uma tragédia que ocorreu com sua filha (fora espancada); seu discurso tem duração de três minutos sem um corte sequer. Durante esse discurso a imagem vai se afastando até que após um minuto e vinte segundos, a câmera atinge outro homem (Corleone) que está de costas para a câmera e escuta a conversa como um psicólogo escuta um paciente dialogando com breves perguntas.

Como verificamos na descrição, temos uma cena a qual permanece três minutos sem corte algum, a câmera afasta o foco lentamente até atingir os dois homens do diálogo e uma mesa entre eles. A permanência da cena sem nenhum corte durante três minutos cria um sentido de testemunho, aumentando a tensão do espectador conforme o personagem aflito implora pela a ajuda de Corleone. Dessarte, a escolha de cortes impacta diretamente a narrativa criando diversos significados para além do texto.
Nos jogos eletrônicos a aparência dos cortes manifesta-se de forma diferenciada. Normalmente ela é prevista pelo jogador, pois o corte é fruto de uma ação que este efetuou, não a forjando arbitrariamente como nos filmes. Assim sendo, o que difere demasiadamente a comunicação dos jogos para com as outras mídias é a interação, que nesse caso entendemos por:

A interação é aquele onde o leitor pode fisicamente modificar o discurso através de diversas interpretações e produzir significado no discurso por si. Um trabalho interativo é aquele onde a interação do leitor é parte integrada da produção do mesmo, na qual a interação é o objeto-signo que indica o tema dos diversos signos e não um meta-signo que indica os sinais do discurso [tradução nossa] (BØGH, 1990, p.89 apud AARSETH, 1997,p.49).

Como exemplo da interatividade nos jogos eletrônicos, utilizaremos o game Resident Evil (Capcom, 1996), todavia para fazê-lo necessitamos compreender como que classificamos os aspectos expositivos de um jogo eletrônico. Como primeiro aspecto temos a interface, vista aqui "menos como estratégias de comunicação e mais como um padrão reconhecível do jogo. É uma descrição do jogo em termos de seu funcionamento e não do que significa" (BRANCO \& PINHEIRO, 2006). Estatuto tecnológico o qual entendemos como um regulador da interação do jogador para com os comandos impostos pelo jogo eletrônico. Por fim o gênero narrativo que é a parte dessa classificação que se encarrega de ambientar, em todos os níveis (histórico, arquitetônico, cenográfico, musical, físico, etc.) o jogo eletrônico.

O jogo eletrônico Resident Evil obtém uma interface denominada third-person-shooter - uma das diversas interfaces de jogos eletrônicos que consiste na visão da câmera em terceira pessoa do avatar (personificação de um conceito, ou uma versão contínua de uma entidadeno qual interage com a diegesis em questão).que é controlado pelo jogador. Seu estatuto tecnológico pode ser um controle do console Playstation ou o teclado e mouse para $P c$ (Personal computer), e seu gênero narrativo é de suspense e terror em uma diegesismista onde encontram-se zumbis entre diversas outras mutações virais.

Os cortes na diegesis desse jogo ocorrem-se apenas quando um jogador sai de uma sala (cômodo) 
e entra em outra sala - uma tela preta como plano de fundo e uma porta marrom apresentam-se como foco no centro da tela e sua maçaneta é girada fazendo com que a porta se abra lentamente - sua duração varia entre dois a cinco segundos. É possível compreender de duas formas os poucos cortes presentes nesse jogo eletrônico: a primeira forma é o corte inserido em função da narrativa - quando um personagem sai da sala e tudo fica escuro por alguns segundo, a tensão sobre a expectativa do imprevisível é assustadora; a outra é a duração do corte para aguardar o tempo de carregamento de arquivos da próxima sala. Um fator complementa o outro por meio da simbiose entre osmateriais e programas, sendo que os materiais representam os signos do jogo com os quais o usuário se relaciona, como por exemplo: jogo ambientado no período feudal teria um material todo voltado para criar um mundo ficcional com elementos de arquitetura, vestimenta, música e tecnologia da época, e os programas representam o significado usual de programa computacional, ambos, material e programa característico de todo e qualquer jogo eletrônico. A câmera nesse jogo desloca-se automaticamente quando o personagem alcança os limiares da tela. Essa questão também é fator relevante na narrativa - enquanto material, corrobora com o clima de terror e suspense, pois o jogador não consegue manipular livremente a câmera podendo apenas observar os ângulos pré-estabelecidos pelo jogo enfatizando sua impotência em controlar as possíveis imprevisibilidades ocorrentes - enquanto programa, apresenta-se com a limitação da tecnologia da época (determinado pelo engine, que é o motor e biblioteca de informações do jogo eletrônico). Esse fator tornou-se uma escolha estética da interface da saga Residente Evil, que parte do primeiro jogo Resident Evil-(Capcom, 1996) até o terceiro jogo denominado Resident Evil - Nemesis (Capcom, 1999).

É comum em jogos eletrônicos essa simbiose entre o limite tecnológico e o desenrolar de uma narrativa. Poderíamos reparar em vários outros jogos eletrônicos e encontrarmos os mesmos aspectos que reforçam essa ideia, como por exemplo, a fisionomia do personagem Mario criado pela Nintendo, o qual possui como características marcantes em sua aparência, um bigode, um macacão e grandes sapatos. A escolha desses elementos físicos fora ditado pela dificuldade gráfica da época de descrever (imageti- camente) um ser humano, já que os primeiros jogos criados tinham como elementos narrativos naves extraterrestes, criaturas sobrenaturais, mas dificilmente humanoides.

Esses exemplos anteriormente apresentados foram inseridos para compreendermos as diferenças da fruição da diégesis entre os jogos eletrônicos e os filmes. Como uma breve conclusão, analisamos que os cortes nos jogos eletrônicos manifestam-se de forma diferente dos cortes no cinema fazendo com que a diegesis dos jogos eletrônicos apresenta-se mais fluida e natural (comparando com o mundo real) já que é o jogador que controla quando e onde o corte acontecerá. Portanto, uma vez discutida as diferenças sobre a diegesis no jogo eletrônico e no cinema, podemos partir para a exposição do conceito de fetichismo da mercadoria, o qual predomina em nosso sistema econômico no mundo real e é transposto de forma equivalente nos mundos ficcionais dos jogos eletrônicos.

\section{O fetichismo da mercadorianos jogos eletrônicos}

O conceito de fetichismo da mercadoria foi criado por Karl Marx (1818 - 1883) como reflexo crítico e filosófico da sociedade capitalista. A partir de então, diversos outros autores reinterpretaram o dito fetichismo da mercadoria ampliando sua visão e implicação no mundo contemporâneo. A característica principal para o modo de produção capitalista é que tudo torna-se mercadoria, inclusive pessoas e lugares. O fetichismo, por sua vez, agrega valor à essa "mercadoria" atribuindo à ela um caráter fantasmagórico.

Desvenda-se o caráter alienado de um mundo em que as coisas se movem como pessoas e as pessoas são dominadas pelas coisas que elas próprias criam. Durante o processo de produção, a mercadoria ainda é matéria que o produtor domina e transforma em objeto útil. Uma vez posta à venda no processo de circulação, a situação se inverte: o objeto domina o produtor. $\mathrm{O}$ criador perde o controle sobre sua criação e o destino dele passa a depender do movimento das coisas, que assumem poderes enigmáticos. Enquanto as coisas são animizadas e personificadas, o produtor se coisifica. Os homens vivem, então, num mundo de mercadorias, um mundo de fetiches (MARX, 1996, p.34). 
Esse conceito interliga uma metodologia totalizante para análise e intervenção na realidade, não meras conceituações. Karl Marx olha para a sociedade capitalista como um organismo sobre três eixos (FONTES, 2010): a expropriação que gera a separação de condições e bens sociais da produção; a exploração do trabalho vivo (pessoas), em contato com o trabalho morto (mercadorias) que enrijecem os meios de produção sob o controle do capitalista; e a dominação que configura-se por meio de formas culturais e ideológicas e divisão hierárquica de classes sociais. Logo, o trabalho, o qual perdeu seu caráter de realização social e individual do ser humano, passoua ser uma atividade hostil pela necessidade de sobrevivência.

Selecionamos duas reportagens, uma feita por Richard Heeks(2010) pela revista online Scientific American, e a outra de Jonathan Campos (2013) pela revista online Gazeta do Povo. Ambas discorrem sobre o mercado de elementos virtuais comprados por dinheiro real, sendo que a matéria de Heeks discorre sobre uma perspectiva histórica e macro, relatando sobre as empresas que trabalham com esse ofício; já a matéria de Campos discorre sobre alguns indivíduos que praticam o gold farmer (fazendeiro do ouro) que consiste em acumular bens nos jogos virtuais para depois vendê-los por dinheiro real. Logo ambas as reportagens discorrem sobre formas de trabalhos inseridas na sociedade capitalista. Nosso intuito, com o estudo dessas reportagens, é se prontificar para a transposição do fetichismo da mercadoriapara a diegesis dos jogos eletrônicos.

O texto de Richard Heeks "Dinheiro real de mundos virtuais" descreve as primeiras manifestações dos gold farmers (fazendeiros de ouro), nome que descreve aqueles jogadores que se dedicam a um jogo eletrônico, normalmente conhecido como Massive Multi-player online role-playing game $(M M O R P G)$, que significa que o jogo eletrônico permite uma quantidade grande de jogadores, para acumular recursos virtuais e depois vendê-los por dinheiro real, normalmente em dólar estadunidense. Essa maneira de jogar demonstrou-se prolífica acarretando na criação de empresas que contratam jogadores para jogar entre dez a doze horas diárias com o intuito de acumular recursos, evoluir os $a v a-$ tares e buscar itens raros de um determinado jogo eletrônico.
Já a reportagem de Jonathan Campos "Jogo online, mas com dinheiro real no RPG" demonstra relatos de experiências de gold farmers do jogo eletrônico Tibia (Cipsoft, 1997). O jogador João Luiz Freitas, que faturou dois mil reais com a venda de um só item virtual e pretende vender dois de seus personagens, cada um por três mil reais, relata que: "Tive que viajar para outro mundo virtual para achar (o item que vendeu). É um dos mais fortes para magos" e "Eu evoluo o personagem para no futuro vendê-lo. Isso é muito comum e eu tenho amigos que ganham muito dinheiro".Como vemos, o jogador enxerga o jogo eletrônico como um campo de trabalho, uma fábrica que transforma dinheiro virtual em dinheiro real e isso só é possível quando temos uma demanda de consumidores que se importam com sua condição "física" e reputação em um mundo ficcional. Com isto posto, por dentro desses dois artigos jornalísticos deparamo-nos com o impacto social e financeiro gerando um novo mercado que se pauta na venda de objetos virtuais, tão importante quanto os objetos do nosso mundo real. Com isso, enfrentamos as seguintes questões: Uma mercadoria do mundo real como: cartucho/cds/arquivos de jogos, consoles, utensílios e computadores, poderia agregar valores diferenciados por conta de uma características presente em um mundo virtual? Como avaliar o preço de um item virtual? Quanto ele custa no mundo real? O fetichismo da mercadoria existe nos objetos do mundo virtual?

\section{O fetichismo da mercadoria no ambiente dos jogos eletrônicos}

Muito do impulso consumista para com os computadores e consoles se dá pelo valor fantasmagórico que a propaganda agrega ao produto e que sua real função e configuração normalmente é incompreendidas pelas pessoas que os consomem. O consumo tecnológico passou a ser então uma prática do "ambiente cotidiano e a atmosfera comum da vida humana, que, com a sua regularidade, imediatismo e evidência, penetram na consciência dos indivíduos agentes, assumindo um aspecto independente e natural" (KOSIK, 2002, p.15). Esse estado do ser humano é denominado por Karel Kosik como o "mundo da pseudoconcreticidade". 
O mundo da pseudoconcreticidade é um claro-escuro de verdade e engano. $\mathrm{O}$ seu elemento próprio é o duplo sentido. $\mathrm{O}$ fenômeno indica a essência e, ao mesmo tempo, a esconde. A essência se manifesta no fenômeno, mas só de modo inadequado, parcial, ou apenas sob certos ângulos e aspectos. O fenômeno indica algo que não é ele mesmo e vive apenas graças ao seu contrário. A essência não se dá imediatamente; é mediata ao fenômeno e, portanto, se manifesta em algo diferente daquilo que é. A essência se manifesta no fenômeno. $\mathrm{O}$ fato de se manifestar no fenômeno revela seu movimento e demonstra que a essência não é inerte nem passiva. Justamente por isso o fenômeno revela a essência. A manifestação da essência é precisamente a atividade do fenômeno (KOSIK, 2002, p.15).

Normalmente os consumidores, ao comprar um computador, se apegam a números que teoricamente representam o valor quantitativo e qualitativo do objeto sem compreender qual sua real função no mecanismo de processamento de um computador e muito menos seu equilíbrio em função dos demais equipamentos que compões todo da máquina. Claramente esse objeto torna-se mistificado pela ignorância dos processos de funcionamento enquanto software e hardware de um console e/ou computador.

Além disso, os jogos eletrônicos, fruto do último quartel do século $\mathrm{XX}$, por sua vez, são um dos maiores responsáveis pelo impulso e desenvolvimento da tecnologia de softwares e hardwares por causa de sua constante demanda de consumo nas variadas faixas etárias. Esse consumo intensificou-se ainda mais com o advento da difusão online de variados jogos eletrônicos; da transposição de jogos para aparelhos portáteis e da competição constante entre jogadores cotidianamente plugados na rede de internet.Por consequência, o jogo eletrônico é o objeto que cria uma demanda desenfreada de consumidores que "necessitam" de melhores e mais atualizadas máquinas para que determinado jogo eletrônico possa ser executado com perfeição (todas as opções de gráficos e som no nível mais alto). Além de todos os fatores anteriormente citados, os mundos virtuais criados para ambientar os jogos eletrônicos fetichizam os computadores e consoles. Isso ocorre quando a aparência do suporte tecnológico apropriase de uma determinada imagem, forma e/ou som de um mundo ficcional que engrandece o produto real, tornando-o superficialmente melhor que os demais com a mesma configuração e programação.
Em suma, o fetichismo existente nos equipamentos de suporte dos jogos eletrônicos se dá pelas seguintes questões: 1) a falta de compreensão do funcionamento de uma máquina (computador/console) gera ignorância e ingenuidade que levam o indivíduo à um vício de renovação tecnológica constante; 2) o aumento da rede de interação dos jogos eletrônicos impulsiona o consumo de tempo e dinheiro no mesmo; 3) a ambientação do mundo virtual dos jogos eletrônicos proporciona um valor agregado ao produto real que utiliza-se de sua temática, quer seja um computador, quer seja um console, quer seja um assessório, provocando assim um caráter místico ao objeto já fetichizado.

\section{O fetichismo da mercadoria em produtos virtuais dos jogos eletrônicos}

Escolhemos o jogo Dota 2 (Valve, 2013) para efetuarmos a análise para elucidarmos essas questões anteriormente levantadas, pois ele, o jogo eletrônico, disponibiliza pela Steam- um mercado comunitário criado pela Valve para combater a pirataria de jogos eletrônicos e vender diversos jogos fornecendo espaço da nuvem para armazenamentos. Além disso, a Steam permite que os jogadores possam vender, comprar e trocar seus itens adquiridos.

Dota 2 utiliza-se da interface denominada MOBA (Multiplayer Online Battle Arena) considerado um e-esporte (esporte eletrônico). Esse jogo comporta dois times de cinco jogadores onde cada jogador seleciona um avatar. O objetivo do jogo é destruir as torres até alcançar o Ancient (centro da base de cada um dos times) para poder destruí-lo e acabar o jogo; os jogadores precisam então defender suas torres e seu Ancient e ao mesmo tempo destruir as torres e o Ancient do time adversário. Seu estatuto tecnológico consiste no domínio do teclado e mouse. Sua forma de jogar pode ser personalizada por cada jogador. Os comandos mudam conforme o avatar que o jogador selecionar, contudo a maioria desses avateres se utiliza do mesmo padrão de comando. Seu gênero narrativo pertence a uma diegesis mista com elementos provindos de diversas referências do nosso mundo real, sempre com um caráter fantasioso abarcando desde espadas e escudos até armas a laser, criaturas humanas (humanoides) até espíritos. 
Equivalente aos esportes, o jogo eletrônico Dota 2 está repleto de fetichismo tanto pelos jogadores, quanto pelos equipamentos que esses jogadores utilizam. Em Dota 2 mapeamos duas formas de fetichismo:1) A primeira é a respeito dos itens (modificam a aparência do avatar) que são lançados no mercado e sua repercussão enquanto valor na venda e compra da comunidade Steam. 2) A segunda questão são as diferenças de preços de um mesmo item (aparentemente) que se difere apenas por estar inserido em algum evento ou atribuir um valor de novidade ou antiguidade.

Um item adquirido ou comprado no jogo eletrônico Dota 2 pode influenciar nas seguintes questões:

1. bonificação de experiência - com esse item seu nível enquanto jogador aumenta rapidamente possibilitando adquirir mais itens;

2. mudança de aparência do avatar - com esse item a roupa, pele, corte de cabelo, entre outras formas de aparência se diferenciam do comum,

3. mudança de animação das habilidades e aparência-com esse item equipado a aparência das habilidades lançadas se diferenciam das comuns.

Nenhuma dessas formas altera os mecanismos do jogo, logo um jogador sem nenhum item tem as mesmas condições de jogo que um jogador abastado de itens.

Figura 1: Ilustração de um avatar retirado do jogo eletrônico Dota 2 sem nenhum item equipado

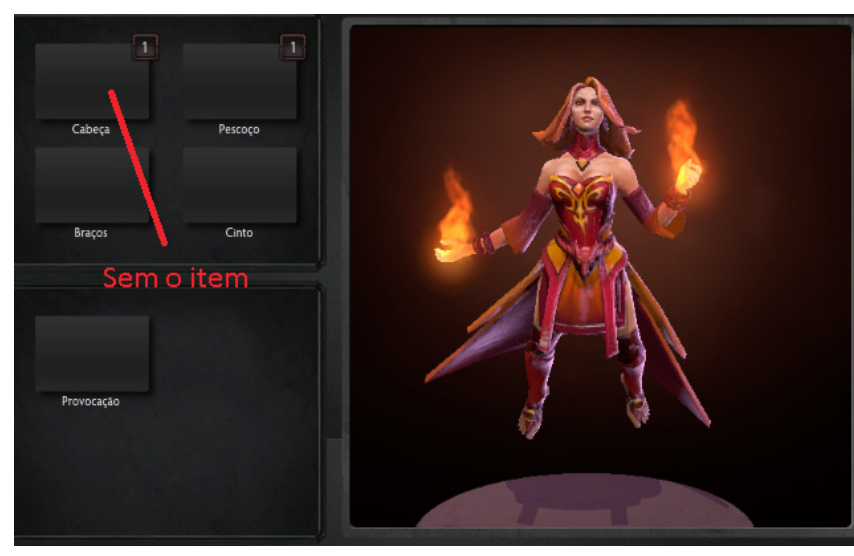

Figura 2: Ilustração de um avatar retirado do jogo eletrônico Dota 2 com um item equipado.

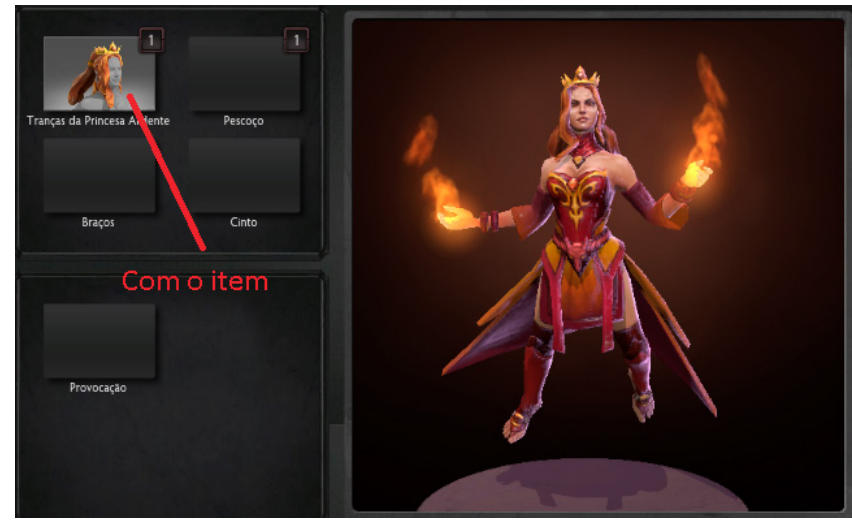

Como pesquisamos, o foco principal da compra de objetos virtuais no jogo eletrônico Dota 2 é adquirir itens diversos (como vemos na imagem o item "Tranças da Princesa Ardente") para tornar seus avatares diferenciados dos demais. Essa perspectiva nos jogos eletrônicos corrobora com a ideia de perversão fetichista de Baudrillard (1968, p.100):

"Estou loco por esse objeto", declaram e, sem exceção, mesmo quando não está incluso na perversão fetichista, mantem em torno de sua coleção um ambiente clandestino, de sequestro, de segredo e de mentira que possui todas as características de uma relação pecaminosa. Esse jogo apaixonado é o que torna esse comportamento regressivo e justifica a opinião a respeito do indivíduo que não coleciona nada, como um cretino e um pobre descartável ser humano. [Tradução nossa]

Muitas vezes a ostentação dos itens no jogo Dota 2 torna-se doentia, pois o jogador passa a jogar para obter os itens e não pelo jogo em si. Para tanto, eles gastam o dinheiro real para garantir um status no jogo, independente de seu desempenho.

Nos eventos (campeonatos), os jogadores apresentam seus avatares personalizados que servem de vitrine para os modelos de roupas, armas, entre outros objetos, sendo que, apenas por serem utilizados pelos jogadores profissionais, considerados celebridades, são atribuídos aos itens equipados nos avatares, uma valorização de seu custo de venda no mercado da Steam.

Segundo o que consta no próprio jogo, temos a divisão crescente de singularidade dos itens:1) Item comum (cor branca), 2) Item distinto (cor azul claro), 
3) item raro (cor azul escuro), 4) item mítico (cor roxa), 5) item lendário (cor roxa escura), 6) item imortal (cor dourada).

Esses itens são adquiridos de través do tempo (duração) que determina o nível em que a conta do jogador se encontra - quanto maior o nível, mais itens o jogador terá; os itens também podem ser adquiridos através da sorte, pois no final de cada partida cada jogador tem uma chance de receber um item; ou os itens podem ser comprados no mercado do próprio jogo Dota 2 ou no mercado da Steam por meio da venda de itens disponibilizados por outros jogadores.

Para o jogador, quanto maior nível de raridade do item, maior a sensação de unicidade e realização pessoal. Essa sensação amalgama o indivíduo que se esforça para se diferenciar entres os semelhantes, como descrito pelo filósofo Gilles Lipovetsky (2005) em sua constatação sobre as repercussões do processo de personalização.

O ideal moderno de subordinação do indivíduo a regras racionais coletivas foi pulverizado, o processo de personalização promoveu e encarnou maciçamente um valor fundamental: o da realização pessoal, do respeito à singularidade subjetiva, da personalidade incomparável, quaisquer que sejam as novas formas de controle e de homogeneização (LIPOVETSKY, 2005, p.17).

Os jogadores inseridos no contexto do Dota 2 necessitam demonstrar superioridade por intermédio dos itens e seu nível de raridade, pois a personalização de seus avatares com itens considerados pelo sistema do jogo como únicos reforça"a auto-representação, humorística no que concerne aos sistemas sociais, narcísica em relação aos sistemas psíquicos" (LIPOVETSKY, 2005, p.127).

A questão de divisão dos itens acopla outros fatores que influenciam em sua personalização. Em Dota 2, além da divisão de raridade dos itens, temos os itens provindos dos eventos temáticos que ocorrem em um determinada data e extinguem-se após seu término. Esses itens normalmente alteram a cor no nome do mesmo, como item amaldiçoado (cor roxa no nome do item), item congelado (cor azul gelo no nome do item), item insculpido (cor laranja no nome do item), entre outros.

A diferença de preços do mercado é determinada pela raridade do item, mesmo que sua aparência dentro do jogo seja a mesma, como observamos na figura a seguir.

Figura 3: Imagem retirada do mercado disponível no servidor da empresa Steam.

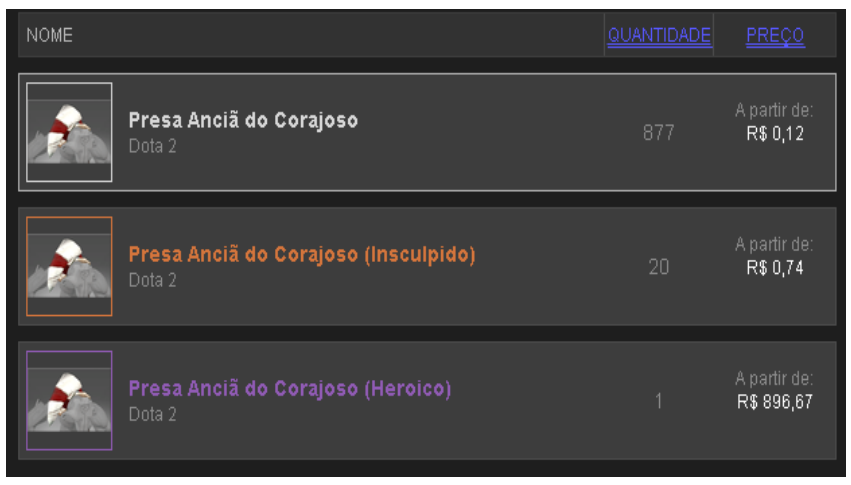

A aparência dos três itens demonstrados na $f$ gura 5 é a mesma, mas a diferença de preço variou entre 0,12 reais até 896,67 reais apenas pelo item ter seu nome pintado de roxo e com a inscrição (Heróico) após o mesmo.

Essa relação está ligada a dois fatores: 1) a novidade do item inserida em um novo evento, 2) a antiguidade e extinção do item de um evento anterior.

[...] todo objeto antigo é belo simplesmente porque sobreviveu tornando-se um sinal de uma vida anterior. É uma curiosidade ansiosa de nossas origens que justapõe os objetos funcionais, sinais de nosso cenário atual, os objetos mitológicos, sinais de um reino anterior (BAUDRILLARD, 1969, p.94).

Como ilustra o teórico, o objeto sobrevive ao tempo tornando-se uma relíquia por conta de um esnobismo e prestígio cultural fazendo com que seu valor de mercado modifique bruscamente. No jogo Dota 2 isso ocorre também: o item descrito na figura 5 como "Presa Anciã do Corajoso (Heroico)" é fruto do evento ocorrido na metade do ano de 2013 e a figura 5 foi tirada no dia 22/06/2014 - um ano após o evento. Como verificamos, o item com custo de 896,67 reais é o único no mercado (Consta o valor de 1 na linha vertical de "Quantidade" encontrado na figura 5) e dificilmente encontraremos outro equivalente. Esse fator gera grande peso para seu consumo em jogadores inseridos nessa ambição narcisista que transforma aquele que antes era apenas um jogador, em um colecionador de itens virtuais. 


\section{Conclusão}

Nosso ponto então consiste na busca dos impactos que os jogos eletrônicos causam em nossa sociedade. Como demonstrado, a diegesis nos jogos eletrônicos é fluida e mimética ao nosso mundo real reproduzindo inclusive nossa estrutura capitalista dentro das formas de interação de compra/ venda/ troca entre os usuários/consumidores, transformando o dinheiro virtual, que possui valor de troca apenas no mercado do jogo eletrônico específico, em dinheiro utilizado no nosso mundo real e vice-versa. Essa questão nos aponta a importância dos futuros estudos relacionados às influências dos jogos eletrônicos, e suas respectivas diegesis, em nosso cotidiano cultural. Portanto, essa interferência entre os mundos ficcionais de diversos jogos eletrônicos e o mundo real carece de atenção e estudo, pois a diegesis dos jogos eletrônicos ocupam cada vez mais espaço em nossas vidas sem que ao menos percebamos.

\section{Referências}

AARSETH, Espen J. 1997. Cybertext: perspectives on Ergodic Literature. London: Johns Hopkins University Press.

BAUDRILLARD, Jean. 1969. El sistema de los objetos. [Tradução: Francisco Gonzalez Aramburu] México.

BRANCO \& PINHEIRO, Marsal Aves e Cristiano Max Pereira. 2006. Uma tipologia dos games. UNIrevista Vol.1, n³ [p.1-8].

BRANDÃO, Jacyntho Lins. 2007. Diegesis em república 392d. Kriterion, Belo Horizonte: $\mathrm{n}^{\circ} 116$ [p.351-366].

CAMPOS, Jonathan. Jogo online, mas com dinheiro real no RPG.Gazeta do Povo:2013. Disponível em: $<$ http://www.gazetadopovo.com.br/tecnologia/conteudo. phtml?id=1434903 $>$. Acessado em 23/06/2014.

FONTES, Virgínia. O Brasil e o capital imperialismo. Teoria e história. Rio de Janeiro: EPSJV/UFRJ, 2010.

GORBMAN, Claudia.1987. Unheard Melodies: narrative film music. Londres: The British Film Institute.

HEEKS, Richard. 2010. Dinheiro real de mundos virtuais. Scientific American Brasil, Disponível em: <http://www2. uol.com.br/sciam/reportagens/dinheiro_real_de_mundos_ virtuais.html $>$. Acessado em 23/06/2014.

JUUL, Jesper. 1999. A clash between game and narrative. Dissertação de Mestrado [91p.] Copenhage: Universidade de Copenhagen, Instituto de língua Nórdica e literatura.
JØRGENSEN, Kristine. 2003. Aporia \& Epiphany in context: computer game agency in Baldur's Gate II \& Heroes of Might \& Magic IV. Noruega: Universidade de Bergen.

KOSIK, Karel. Dialética do concreto. Rio de Janeiro: Paz e Terra, 2002.

LIPOVETSKY, Gilles. 2005. A era do vazio - ensaios sobre $o$ individualismo contemporâneo. [tradução Therezinha Monteiro Deutsch] São Paulo: Barueri: Manoele.

MARX, Karl. 1996. O capital - crítica da economia política. [Tradução: Círculo do Livro] São Paulo: Editora Nova Cultura.

MIRA, David Moedas. 2012. Das sombras de Platão ao realismo de Iracema: a representação do real no cinema. Portugal: Universidade Nova de Lisboa, Faculdade de ciências sociais e humanas.

MURCH, Walter. 2004.Num piscar de olhos - a edição de filmes sob a ótica de um mestre. [tradução: Silman James Press]. Rio de Janeiro, Jorge Zahar Editor.

Recebido em: 01/12/2014

Aceito em: 02-01-2015 